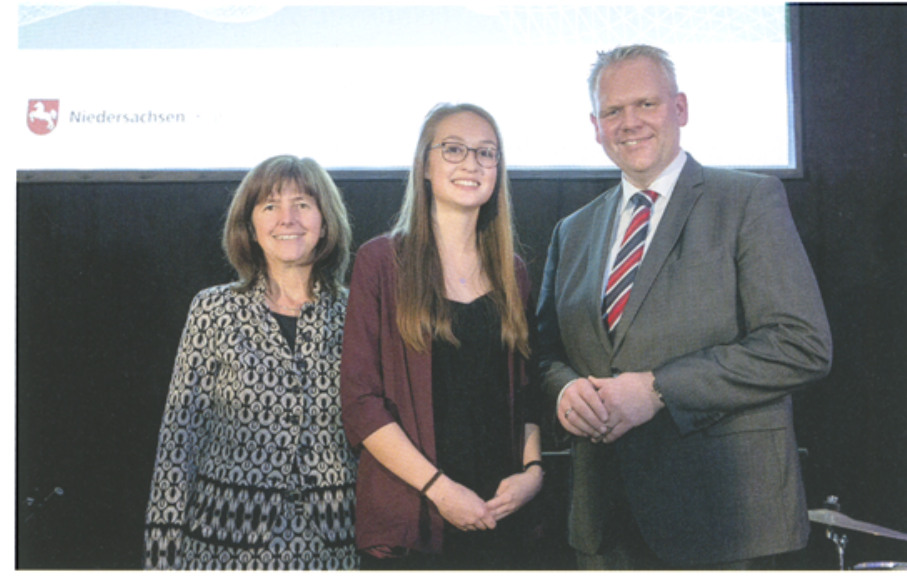

Prof. Monika Sester, Preisträgerin Lucy Icking und Niedersachsens Wissenschaftsminister Björn Thümler. Foto: Sven Brauers

Prof. Monika Sester, Leiterin des Instituts für Kartographie und Geoinformatik der Leibniz Universität Hannover, freut sich sehr über die Auszeichnung von Lucy Icking: „Solche Preise sind ein großer Ansporn für die Kandidaten, sie werfen aber auch ein positives Licht auf deren

Disziplin“. Lucy Icking konnte während der feierlichen Preisverleihung überzeugend darlegen, welche Bedeutung Geodaten und die automatische Datenanalyse haben - unter anderem im Kontext von Künstlicher Intelligenz für das Autonome Fahren.

\section{Universität Bamberg}

\section{Matthias Moeller zum apl. Professor ernannt}

Prof. Dr. Matthias Moeller wurde wissenschaften am Lehrstuhl für im Dezember 2017 vom Präsi- Physische Geographie der Univerdenten der 0tto-Friedrich- sität Bamberg zum Privatdozent Universität Bamberg, Prof. Dr. Go- ernannt worden. Er hat zudem seit dehard Ruppert, zum außerplan- Oktober 2010 eine Professur für mäßigen Professor an eben dieser Kartographie, Geographische InUniversität ernannt. Matthias formationssysteme und FernerMoeller war im April 2010 von der kundung an der Beuth HochschuFakultät für Geistes- und Kultur- le für Technik in Berlin inne.

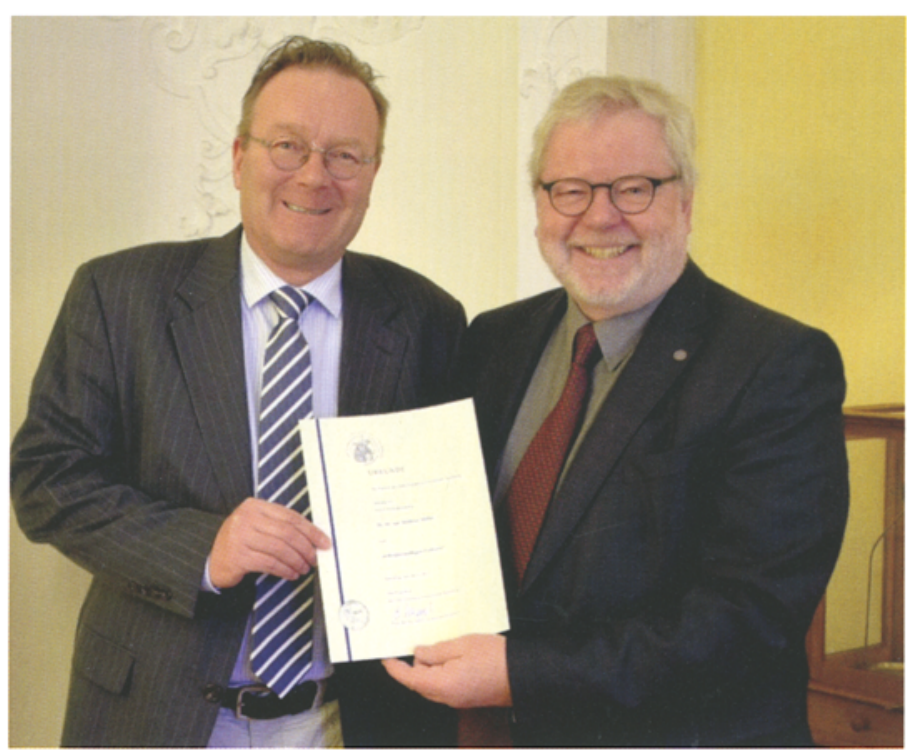

Prof. Ruppert (rechts) und Prof. Moeller bei der Übergabe der Ernennungsurkunde (॰ Pressestelle Universität Bamberg)

\title{
Rezensionen
}

\section{Rathmann, M.:}

\section{- Tabula Peutingeriana - Die einzige Weltkarte aus der Antike}

Rathmann, M.: Tabula Peutingeriana - Die einzige Weltkarte aus der Antike. Verlag Philipp von Zabern - WBG, 2016, 2., unveränderte Auflage 2017. $112 \mathrm{~S}$. mit 41 farb. Abb., 33 s/w und 33 farb. Tafeln der Tabula in Einzelteilen, Bibliogr. u. Ortsreg., Gzl. mit Prägung. $249 €$, ISBN 978-3-8053-5101-0

Seit der Homo sapiens aus dem Inneren Afrikas aufgebrochen ist, sich in der Welt zu verbreiten, entwickelte er sich ein lebensräumliches Gedächtnis. Seit er zu zeichnen gelernt hat, macht er davon Landkarten. Die allermeisten gingen verloren, es sei denn, sie überlebten zum Beispiel als prähistorische Petroglyphen, als Felsritzungen wie im Val Camonica (Provinz Brescia, Norditalien). Verloren gehen, das geschieht, selbst seit Karten gedruckt werden, und mit vie Glück bleibt vielleicht von der ganzen Auflage ein Stück übrig. Die von Martin Waldseemüller und Matthias Ringmann entworfene und 1507 in einer Auflage von höchstwahrscheinlich 1.000 Abzügen gedruckte Weltkarte Universalis Cosmographia gibt es nur noch einmal. Sie schlummerte in der Schlossbibliothek Wolfegg und wurde vom Kartographiehistoriker Josef Fischer 1901 entdeckt, in einem Codex eingebunden. Man erinnert sich: Vor einigen Jahren ging sie in die Kongressbibliothek Washington, wo sie sorgfältig an einem Ehrenplatz gehütet wird, denn auf ihr ist erstmals „America“ eingetragen.

Es grenzt an ein Wunder, dass mit der Tabula Peutingeriana eine einzige der antiken Weltkarten

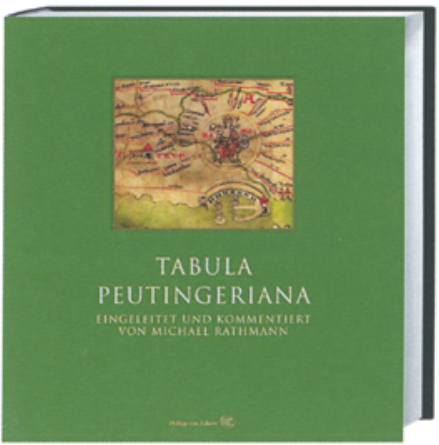

auf uns gekommen ist. Es handelte sich um eine Bandrollkarte von plusminus $34 \mathrm{~cm}$ Höhe und ausgerollt 6,82 m Länge, zusammengeklebt aus 11 Teilstücken (Segmenten) zwischen 57 und $67 \mathrm{~cm}$ Breite. Dargestellt wird stauch-gedehnt das Imperium Romanum von der Südostecke Britanniens bis Kleinasien sowie Vorderasien und Vorderindien, die in der Antike bekannte Welt. Im Westen fehlt offensichtlich das erste Segment mit dem westlichen Anfang des römischen Reiches. Im dargestellten Gebiet liegt ein rotes Strichnetz mit Stationsknicken, farbigen Kartenzeichen für herausragende Orte zumeist an Netzknoten, Ortsnamen und Meilenmaßen in römischen Zahlen in dunkler Tinte. Die Strichlängen zwischen zwei Knicken liegen zwischen weniger als 1 und $10 \mathrm{~cm}$ und mehr, ohne konstantes Verhältnis zu den angeschriebenen Entfernungen, wie durch die Stauchdehnung auch nicht anders zu erwarten. Die gelehrte Welt erfuhr davon im ersten Jahrzehnt des 16. Jahrhunderts. Es hatte nämlich der $\mathrm{Hu}-$ manist Conrad Celtis bei der damals üblichen Recherche in Klosterbibliotheken nach antikem Schriftgut die Karte in einer süddeutschen Klosterbibliothek entwendet - viel spricht für Reichenau - und noch vor seinem Tod 1508 seinem Freund, dem Humanisten und Augsburger Ratsherrn Konrad Peutinger, überlassen mit 